\title{
MODELOS Y FORMATOS DE DEBATES ELECTORALES CARA A CARA POR TELEVISIÓN
}

\author{
Benjamín Marín. Universidad de Valencia (España)
}

\section{Definición, modelos y formatos}

El debate es un género periodístico de carácter especial en relación con el resto de elementos de la campaña electoral que se engloba dentro de la informaciónespectáculo, una de las características que definen la comunicación política actual. Para Mariano Cebrián "se caracteriza por la confrontación ideológica. Desde el primer momento aparece la polémica y el enfrentamiento entre ambos". El formato de los debates televisivos supone una personalización de la política, ya que ofrece a los candidatos una buena oportunidad para el cultivo de su propia imagen.

Existen distintas posibilidades de formato para la celebración de debates en función del número de participantes: a tres bandas, a cuatro, a cinco, a seis. El más atractivo desde el punto de vista del medio televisión y del electorado es la modalidad a dos bandas: el cara a cara. Es un formato que cuando enfrenta a los líderes de los partidos mayoritarios o a los candidatos a la presidencia del gobierno o el estado constituye el acontecimiento más importante de la campaña. En el caso de que los intervinientes sean "segundos espadas" o se trate de debates sectoriales o especializados, el interés y la audiencia baja ostensiblemente y se aleja del gran debate que protagoniza una campaña moderna ${ }^{2}$.

\subsection{El modelo norteamericano}

\subsubsection{Definición}

El debate americano standard suele tener por norma general una duración de 90 minutos y los candidatos están de pie detrás de un atril. No se trata de un debate estrictamente cara a cara sino de una comparecencia ante un periodista o un grupo de ellos. No suele haber tiempo para una introducción o presentación, ya que se entra directamente en los turnos de preguntas. Cada periodista comienza con una pregunta a uno de los candidatos, que tiene dos minutos para responder. El otro candidato tiene un minuto para poder hacer la réplica. Cuando finaliza la entrevista a este candidato, el propio periodista hace lo mismo con el otro contendiente. $Y$ así todos los periodistas hasta el final. De todas formas este "modelo americano" ha evolucionado y tiene hasta tres formatos, cada uno con sus peculiaridades concretas. El formato más antiguo es el que utiliza un atril por delante de los candidatos. Los otros son más modernos y los candidatos se sientan en una especie de taburete, una circunstancia que puede perjudicar al que

\footnotetext{
${ }^{1}$ CEBRIÁN HERREROS, Mariano. Información audiovisual.Concepto, técnica,expresión y aplicaciones. Editorial Síntesis.Madrid,1995. Pag.340.

2 Mirar Cuadro 1 "Audiencias de los otros debates" en el epígrafe 3.6.- de este artículo.
} 
es más bajo. También se da el caso de que los candidatos debatan detrás de una mesa, aunque es el menos utilizado. Algo común en todos estos formatos es la presencia de público, ya que la incorporación de este elemento supone un paso más en la consideración de estos programas informativos como "talkshows". Además, para los candidatos es una cuestión más a superar porque no es lo mismo actuar sólo para la televisión que para cientos de personas que los examinan en vivo y en directo.

\subsubsection{Precedentes}

Antes de que se produjera el nacimiento de la televisión hubo batallas dialécticas entre candidatos a un puesto dentro de la política. Podríamos considerar como precedentes de ${ }^{1}$ los debates televisados las siete comparecencias públicas que enfrentaron a Stephen Douglas y Abraham Lincoln entre agosto y octubre de 1858 por un puesto en el senado. Ambos no tenían el privilegio de contar con la radio y la televisión pero sí con la prensa, que amplificó el efecto de aquellos debates. Unos duelos que se llevaron a cabo frente a audiencias que se reunían en los diferentes distritos electorales de Illinois y que variaron de 1.500 a varios miles de espectadores. La mecánica de estos debates era la siguiente: 3 horas de duración, turnos de palabra entre cada candidato, diálogo entre ellos con preguntas y respuestas. La medición de los tiempos de intervención es otra característica distintiva y exportable desde el principio: 60 minutos la intervención de apertura, 90 minutos la réplica y 30 minutos la duplica ${ }^{3}$. En la época de la radio el debate más conocido fue el que se llevó a cabo entre Thomas Dewey y Harold Stassen en las primarias presidenciables de 1948, debate que estuvo centrado en la legalidad de las actividades del partido Comunista de Estados Unidos.

\subsubsection{El nacimiento americano: Kennedy-Nixon (1960)}

La puesta en escena de un duelo entre dos candidatos que se exhiben cara a cara ante las cámaras de televisión sitúa al marketing político en otra dimensión, ya que el telespectador compara a las dos partes que se enfrentan entre sí. El primer gran duelo de la historia es el que enfrentó ante las cámaras de televisión americana a Richard Nixon y a John Fitgerald Kennedy en lucha por la presidencia de los Estados Unidos. Era la campaña electoral de 1960. Entre los meses de septiembre y octubre hubo cuatro debates, cuyas intervenciones duraron entre 8 y 3 minutos. El primero, celebrado en Chicago, fue el decisivo y está concebido como el gran paradigma de los debates. Además, ese año, 1960, puede considerarse precisamente por esos debates, como el del nacimiento de la comunicación política moderna.

\section{a) En busca de formato}

Doce reuniones entre los representantes de los partidos políticos y las televisiones

\footnotetext{
${ }^{3}$ ROSPIR Zabala, Juan Ignacio, Democracia mediática y campañas electorales, Capítulo 2: "La globalización de las campañas electorales". Ariel Comunicación. Madrid, 1999. Pág. 77
} 


\section{MODELOS Y FORMATOS DE DEBATES ELECTORALES CARA A CARA POR TELEVISIÓN}

tuvieron que celebrarse por tal de definir el formato y la mecánica del debate. En una de ellas, celebrada el 31 de agosto, las cadenas de televisión propusieron el formato de Oregón, que había servido a los demócratas en las primarias presidenciales para enfrentar a Humphrey y Kennedy. Este formato consistía a priori en un cara a cara porque los candidatos después de una breve exposición se interrogaban entre ellos sin la presencia de periodistas que le hicieran preguntas. Los propios partidos desestimaron este formato porque lejos de enfrentarse, Humphrey y Kennedy no se habían atacado, con lo que el debate había perdido interés y dramatismo.

Debates Presidenciales en Estados Unidos (1960)

\begin{tabular}{|c|c|c|}
\hline Emisora & Fecha v hora & Candidatos \\
\hline CBS & $\begin{array}{l}26 \text { / Septiembre /1960 } \\
\text { 9"30 - 10"30 p.m. }\end{array}$ & J.F. Kenndycontra R.M. Nixon \\
\hline NBC & $\begin{array}{l}\text { 7/ Octubre/1960 } \\
\text { 7"30 - 8"30 p.m. }\end{array}$ & J. F.Kenndy contra R.M. Nixon \\
\hline$A B C$ & $\begin{array}{l}\text { 13/ Octubre/1960 } \\
\text { 7"30-8"30 p.m }\end{array}$ & J.F. KennedycontraR.M. Nixon \\
\hline$A B C$ & $\begin{array}{l}\text { 21/Octubre/ } 1960 \\
10^{\prime \prime} 00-11^{\prime \prime} 00 \text { p.m. }\end{array}$ & J. F. KennedycontraR.M. Nixon \\
\hline
\end{tabular}

Fuente: S. KRAUS. Televised presidential debates, Lawrence Erlbaum Associates, Publishers, Hillsdale, New Jersey, 1988, pag.34.

El formato final aprobado para el primer debate constaba de una breve presentación del moderador a los candidatos. Por sorteo, uno de ellos comenzaba una exposición de 8 minutos, después, el otro. Acabada las exposiciones empezaba el estricto turno de preguntas de los cuatro periodistas a los debatientes. Unas preguntas sintéticas sin posibilidad de comentario a la respuesta de los candidatos (con ello se pretendía evitar cualquier favoritismo a algunos de los contendientes). Sólo los políticos podían hacer réplicas. El debate acababa con una declaración final de los candidatos y unas palabras de despedida del moderador. Un moderador que, a diferencia de los periodistas, estaba sentado detrás de una mesa en el escenario junto a los candidatos. Delante de ellos pero fuera de este escenario, que tenía una altura considerable, estaban situados los periodistas que formulaban las preguntas. Los candidatos estaban sentados a ambos lados del moderador y sólo cuando les tocaba su turno se dirigían a su "tribuna" (atril) para contestar a las preguntas de los informadores. La mecánica de este primer debate se siguió en los otros tres en sus aspectos fundamentales. Para que pudieran tener lugar estos acontecimientos políticos a dos bandas hubo que cambiar la ley. El Congreso suspendió la vigencia de la Sección 315 de la Ley Federal de Comunicaciones, que establecía igualdad de oportunidades para todos los candidatos y obligaba a dar el mismo trato a los otros 
catorce candidatos menores que se presentaban a la elección presidencial ${ }^{4}$.

El representante del Partido Republicano, Richard Nixon llegaba a aquellas elecciones después de 8 años como vicepresidente. Por su parte, el joven demócrata Kennedy luchaba en ese momento por quitarse la etiqueta de niño bien e inexperto que los republicanos le habían puesto. En este contexto, Kennedy, bien asesorado por su equipo, lanzó el reto a Richard Nixon de un debate en televisión.

De hecho, Kennedy logró el apoyo de dos asesores de relaciones públicas brillantes, como Pierre Salinger, que llevó la prensa escrita y Leonard Reinsch , que se encargó de la televisión. Para familiarizarse con el medio, Kennedy aceptó someterse a clases de cómo actuar, quizás fue el primer político en hacerlo.

Richard Nixon era un político con mucha más experiencia que Kennedy pero cometió el error de aceptar el debate con un inexperto que tenía mucho que ganar y poco que perder en aquel duelo. A Nixon se le ocurrió tener los cuatro debates pensando que ganaría al tener más experiencia, aunque sus asesores ya le habían advertido que Kennedy, que era el candidato menos conocido, iba a ser probablemente quien sacase más partido de esta experiencia ${ }^{5}$. No se equivocaron los asesores de Nixon. Además de la ventaja que Kennedy le sacó en preparación del debate desde el punto de vista de la televisión. Nixon tuvo en su contra una nefasta puesta en escena que exhibió ante los telespectadores convertidos en electores. Además, desde el punto de vista físico no era un hombre atractivo para la televisión, no era telegénico. En el debate iba afeitado, pero a pesar de ello, su negra y cerrada barba dio la imagen en pantalla de estar mal cuidada, y le proyectó una sombra sobre sus mejillas a consecuencia del maquillaje que le hicieron precisamente para ocultarla. Tan es así que en el monitor de televisión esas sombras daban la sensación de que no se había afeitado.

De hecho, la oposición había jugado bastante con este argumento durante la campaña. Incluso se sacó un célebre slogan: "¿Le compraría usted a este señor un coche usado? La respuesta era obviamente no, porque le ponían cara de gángster. O, ¿lo cogería usted en autostop?, y aparecía como alguien sospechoso.

El asunto de la barba fue negativo para Nixon, ya que encima se vio aumentada por el efecto de una camisa blanca, un color inapropiado para la televisión en color, pero sobre todo en blanco y negro, que era la única existente en ese momento. Además vistió un traje color gris que le produjo unos reflejos en la camisa blanca por la superposición con el fondo del decorado, que también era gris. Por si fuera poco, Nixon apareció en la imagen con sudor en el rostro. Tampoco le favoreció nada la iluminación del estudio, ya que sus ojeras y su larga nariz tuvieron que soportar unos focos en picado vertical que le ocasionaron grandes sombras, aparentándole más edad de la que tenía.

\footnotetext{
${ }^{4}$ MUÑOZ ALONSO, Alejandro. Política y nueva comunicación. Op. Cit. Pag. 145

5 MAAREK. Philippe J. Marketing político y comunicación. Claves para una buena información política. Barcelona,1997. Pág. 31. Op. Cit anterior
} 
A eso hay que añadir más contratiempos, ya que aquel día sufría una inflamación en la rodilla que su rostro no pudo disimular. Todos estos detalles endurecieron más su imagen ya de por sí dura, como de pocos amigos. En definitiva, la impresión que produjo fue mala y por contra no resistió la comparación con su contrincante. Se supone que aquel Nixon de 1960 no tuvo consejeros que le asesorasen bien en sus apariciones personales en la televisión, o si los tuvo no estuvieron demasiado acertados. Su imagen le malsirvió y los dos elementos pugnaron: la buena imagen de Kennedy - desfavorablemente para Nixon-, y la propia mala imagen de Nixon. Frente al sudoroso Nixon estaba un hombre joven, atractivo, de dicción brillante y con un programa romántico basado en las tradiciones del país: "La Nueva Frontera". Su estilo distinto encandiló y conquistó muchos votos desde el principio del debate, que inició de esta forma: ". En la elección de 1860 Abraham Lincoln afirmó que la cuestión era si esta nación podía subsistir mitad esclava y mitad libre. En la elección de 1960 ... la cuestión es si el mundo subsistirá mitad esclavo y mitad libre"6.

Kennedy estuvo también mejor asesorado en materia de vestuario que su contrincante. Vistió un traje azul oscuro, que destacó del fondo gris, con una camisa azul que mató los brillos y reflejos que da el blanco. Además del bronceado que lucía, la propia luz del plató también le favoreció, ya que en lugar de darle sombras le dio una gran cantidad de reflejos a su cabello castaño, lo que aún acentuaba más su telegenia natural. Se mostró innovador, simpático, sonriente, casi encantador y difundía un mensaje renovado y atractivo. En conjunto su actuación técnica y profesionalmente estuvo muy bien preparada.

\section{b) Y ganó}

Este primer debate fue para algunos especialistas clave en el triunfo de Kennedy en las elecciones. Fue concebido como antológico y de ahí se explica el valor de mito que se le ha conferido dentro del campo de las campañas electorales y de la comunicación política. El debate fue seguido por 77 millones de personas, según la firma Nielsen. Sin embargo, la mayor audiencia se situó en el segundo y el tercero con 80 y 82 millones respectivamente porque se programaron a las siete y media de la tarde, un horario que permitió la asistencia de los niños, y de los adultos que acostumbraban a retirarse antes a la cama.

Kennedy ganó el primer debate frente a Richard Nixon pero en el cómputo general de los cuatro debates los sondeos otorgaban un empate, ya que la población pensó que los dos candidatos estuvieron igual en dos de los debates $\left(2^{\circ}\right.$ y $\left.4^{\circ}\right)$, y de los otros dos, uno fue concedido a Kennedy $\left(1^{\circ}\right)$ y otro a Nixon $\left(3^{\circ}\right)$. Después del primer debate Kennedy logró el favor del $49 \%$ de los electores frente al $46 \%$ de su oponente mientras que el día anterior al debate, el 25 de septiembre, iba un punto por debajo (46\% a 47\%). Sin embargo, el 26 de septiembre, 5 días después del último debate, los dos candidatos estaban empatados con un $48 \%$, lo que

\footnotetext{
${ }^{6}$ WHITE, Theodore. 1982. Ver en Política y nueva Comunicación, de Alejandro Muñoz Alonso. Op.Cit. Pag. 145.
} 
minimiza el impacto real de los debates en la votación. Si hubo influencia en el voto fue pequeña y en cualquier caso no se le puede otorgar la elección de Kennedy exclusivamente al éxito que tuvo por su actuación ante las cámaras en los debates. Lo que es incuestionable es que salió más beneficiado después de ellos, ya que mejoró su imagen en experiencia y capacidad en unas elecciones que se decidieron por menos de 100 mil votos (Kennedy 50"1\% - Nixon 49"9\%), una muestra ínfima para el electorado de los Estados Unidos en esos momentos pero suficiente para que Kennedy se proclamara presidente de los Estados Unidos. Su contrincante perdió, posiblemente si no hubiera aceptado el reto hubiera llegado a ser presidente, pero aprendió la lección.

Cabe reseñar el diferente impacto que tuvo el debate sobre el electorado en aquellos que lo siguieron por televisión respecto a los que lo hicieron por la radio. Estos últimos seguían dando como favorito a Richard Nixon de cara al triunfo final pero los que lo vieron por televisión otorgaban la victoria a Kennedy. La razón estribó en que no era el discurso verbal el que había modificado la relación con los candidatos sino la imagen. El mismo discurso, las mismas promesas, el mismo contenido en cuanto a cada tema daba como vencedor a un candidato si lo había escuchado por la radio o a otro si lo había visto por la televisión..

\subsubsection{Otros debates hasta la actualidad}

A diferencia de las elecciones de 1960, en 1964 no hubo debates entre los dos candidatos a la presidencia del gobierno. Los rivales en aquella campaña eran Lyndon B. Johnson, vicepresidente con Kennedy, que fue el que lo sustituyó tras su asesinato, y el conservador republicano Barry Goldwater. Johnson consideró que tenía poco que ganar en un debate al encontrarse en la misma posición de Nixon en los comicios de 1960. Tampoco hubo debates en las campañas de 1968 y 1972 debido a la cura de humildad que tuvo que hacer Nixon después de la derrota televisiva de 1960. Nixon le hizo caso a sus asesores y no volvió a aceptar ya un combate televisivo. Asumió que no era nada telegénico y que no debía aparecer en directo. Todo cambió desde entonces en cuanto a sus intervenciones en la pequeña pantalla. Todos sus spots publicitarios fueron grabados previamente cortando y triturando planos para ganar con el montaje el dinamismo que le faltaba a la persona ${ }^{7}$. Nixon aprendió mucho cuando se dejó convencer por un joven realizador de televisión de 27 años, Roger Ailes, para que, con naturalidad, se dejara grabar primeros planos. Lo que Nixon estaba haciendo no era otra cosa que aceptar las herramientas que contribuyen a aumentar la popularidad de las estrellas de televisión. Su imagen cambió con el paso de los años gracias a sus publicitarios, ya que se dejó llevar. Su tono se volvió mesurado y sereno, el que correspondía al partido republicano conservador que representaba. $Y$ es que después de lo sucedido con Nixon, los candidatos a la Casa Blanca de uno y otro partido se negaron cautelosamente a aceptar el desafío en las elecciones frente a millones de espectadores hasta muchos años después del histórico duelo.

\footnotetext{
7 IZQUIERDO NAVARRO, Francisco. La publicidad política. Oikos-Tau. S.A.

Barcelona,1975Pag.199
} 


\section{a) Ford-Carter (1976)}

Y fueron dieciséis los años que tuvieron que transcurrir. En 1976 tuvo lugar otro debate decisivo, en esta ocasión los protagonistas fueron Gerarld Ford y James Carter, que se enfrentaron en tres ocasiones ante las cámaras de televisión. Fue Ford el que aceptó el reto de un joven inexperto Jimmy Carter.

En el primer debate sucedió una anécdota que demuestra que estos debates buscan el impacto en los millones de espectadores que los están viendo en directo y no en aquellos que lo presencian en vivo en el estudio. Tuvo lugar en Filadelfia y había público presenciándolo. Cuando estaba acabando el programa hubo un fallo de sonido pero no de imagen. El debate, que estaba siendo seguido por muchos millones de personas en directo, quedó ininterrumpido durante 26 minutos, y a lo largo de ese tiempo los dos contrincantes estuvieron de pie sin hablarse entre ellos, sin hacerlo con sus asesores y sin moverse del sitio. A lo largo de ese tiempo la señal visual llegaba a los receptores de los americanos. Cuando se solucionaron los problemas de sonido el debate se reanudó como si no hubiera pasado nada. La audiencia que importaba eran los millones que veían la televisión, no los centenares presentes en la sala ${ }^{8}$.

Ambos candidatos se prepararon de forma concienzuda aunque el demócrata contó posiblemente con mejor preparador y mejor sparring. El mismo Carter superó en la forma y en el fondo al candidato republicano aunque también influyó un fallo de contenido de Ford, que posiblemente le costó las elecciones ${ }^{9}$.

Se equivocó, perdió ante las cámaras y perdió las elecciones. Gerald Ford había supuesto que le convenía participar en algunos de los debates de carácter decisivo, pero ocurrió que no le salieron bien los cálculos ${ }^{10}$.

\section{b) Reagan-Anderson: Carter el gran derrotado (1980)}

En 1980, la Liga de Mujeres Votantes invitó al candidato independiente Anderson a participar en un debate con Reagan y Carter, pero éste último no quiso ir porque no le interesaba que fuera a tres y prefería hacerlo sólo con Reagan. Ronald Reagan y Anderson se enfrentaron en un debate retransmitido por la CBS y la NBC aunque no por la ABC. El perdedor fue el gran ausente.

\section{c) Reagan-Carter (1980)}

En aquella primera campaña Reagan tuvo como asesor a Harry Treleaven, el mismo que le había llevado la campaña de la victoria a Nixon en 1968. Treleaven temía que Reagan apareciera en pantalla dando la impresión que estaba ensayando un papel y dedicó sus esfuerzos a mejorar la calidad de su actuación. Su candidato ya había adquirido la disciplina de no decir lo primero que se le

\footnotetext{
${ }^{8}$ RANNEY, A. en Política y nueva comunicación. Op. Cit. Pags: 145 y 146.

${ }^{9}$ Mirar epígrafe 1.3.- de este artículo titulado El efecto multiplicador

${ }^{10}$ MAAREK. Philippe J. Marketing político y comunicación. Op. Cit anterior. Pag.35
} 
pasaba por la cabeza y cada vez parecía más relajado y presidencial.

Y llegó el día del debate, el 28 de octubre, y al igual que sucedió 20 años antes en el debate entre Kennedy y Nixon, los espectadores otorgaron la victoria a Reagan pero los radioyentes a Carter, lo que volvió a demostrar la supremacía de la imagen sobre el discurso en televisión. Carter dominó los hechos y los temas, sus respuestas fueron más sólidas y dio la impresión que Reagan jugaba a la defensiva. Roland Perry lo cuenta así: "La impresión de los telespectadores fue totalmente distinta. Reagan tenía más aspecto de presidente que el propio Carter. Después de los nervios del principio se sintió a gusto y se relajó más rápidamente. Carter, por el contrario parecía más nervioso todo el tiempo y, al igual que Nixon dos décadas antes, daba la sensación de estar inhibido y crispado ante su oponente. Estuvo serio y frío, mientras que Reagan fue capaz de sonreír, a veces con amabilidad y otras con picardía" ${ }^{11}$.

Reagan fue el ganador de un debate, que con 80 millones de espectadores batió registros de audiencia. Muchos analistas coinciden en que este debate fue clave para que Reagan aumentara su ventaja sobre Carter. Aquella noche Reagan demostró que la televisión sería a partir de ese instante su mejor aliada.

\section{d) Reagan-Mondale (1984)}

En esta época los debates ya estaban totalmente institucionalizados. Los debates entre estos dos contendientes no hicieron más que confirmar el triunfo imparable del reaganismo. En uno de esos debates, el maestro de la palabra incluso hizo reír al propio Mondale. Reagan entonces era ya el presidente de los Estados Unidos de mayor edad con 73 años. En pleno debate, Mondale, que tenía 20 años menos, le hizo un comentario despectivo relativo a su avanzada edad. Reagan le devolvió el ataque y le contestó: "No voy a explotar con propósitos políticos la juventud e inexperiencia de mi oponente".

\section{e) Bush-Dukakis (1988)}

Se enfrentaron en dos ocasiones en esta campaña, bajo el patrocinio de la Comisión de Debates Presidenciales ( grupo formado por los dos grandes partidos) el 25 de septiembre, y el 13 de Octubre bajo la supervisión de la Liga de Mujeres Votantes. Estos debates no fueron duelos cara a cara en la línea Kennnedy-Nixon. Ninguno de los dos aceptó un enfrentamiento final de campaña. Se trató de una comparecencia ante un plantel de periodistas que les formulaban preguntas. Los contendientes no estaban sentados frente a frente sino que estaban en butacones dispuestos de forma paralela. Ellos no se contestaban entre sí, hablaban de forma alternativa y en respuesta a los interrogantes de los periodistas. En el primer debate Dukakis consiguió cierta ventaja sobre Bush. Después de anular la diferencia de 24 puntos de ventaja con la que partió Dukakis tras la convención demócrata, las encuestas señalaban ya la previsible victoria del candidato republicano.

\footnotetext{
${ }^{11}$ PERRY, Roland. Elecciones por ordenador.Tecnos.Madrid.1986.Pag.122
} 
El segundo debate era por tanto una última oportunidad para que Dukakis recuperara la delantera. José Miguel Contreras en su libro Vida política y televisión explica la pregunta de un periodista y la respuesta de Dukakis que acabó hundiéndole en el debate. "El presentador de la CNN Bernard Shaw se dirigió al candidato demócrata en estos términos: si su mujer KittDukakis fuera violada y asesinada isería partidario de la pena de muerte para el asesino ? El político eludió la respuesta directa, divagó sobre el horror de la criminalidad... Finalmente afirmó que también en este caso sería contrario a la pena capital... El misil de Shaw alcanzó la línea de flotación de Dukakis. Los republicanos habían insistido en crear una imagen de Dukakis muy despersonalizada, muy blanda... La frialdad de la respuesta de Dukakis ante la brutalidad y la contundencia de la pregunta fue un contraste muy fuerte excesivo. Los norteamericanos no estaban dispuestos a admitir tener un presente que diera la sensación de "no tener sangre en sus venas", tal y como afirmó un periódico al día siguiente" ${ }^{12}$.

Como resultado de este debate, Bush ratificó la ventaja que le venían dando las encuestas mientras que Dukakis no logró suscitar el movimiento de simpatía que le hacía falta para ganar.

\section{f) Bush-Clinton-Perot(1992)}

Los tres candidatos estaban sentados en una especie de taburete alto sin atril. Algunos autores dicen que esa circunstancia perjudicó a la imagen de Ross Perot porque era más bajo que sus dos contrincantes y, a diferencia de ellos, los pies no le llegaban prácticamente al suelo. El hecho que un candidato saliera perjudicado por un modelo de formato fue motivo de crítica por parte de algunas cadenas de televisión norteamericanas.

En esas elecciones presidenciales hubo tres debates entre los tres aspirantes. Fueron programas que tuvieron 80,87 y 89 millones de telespectadores respectivamente, lo que significó superar el récord de audiencia del debate entre Reagan y Carter de 1980. Pero no sólo los debates presidenciales tuvieron estas espectaculares audiencias, el que celebraron los candidatos a la vicepresidencia registró una increíble cifra de 72 millones.

\section{g) Clinton-Dole (1996)}

Protagonizaron dos debates, el primero tuvo un audiencia de 46 millones y el segundo 36. En un teatro de Hartford, en Connecticut, el demócrata Bill Clinton se enfrentó al republicano Bob Dole. Los tiempos estaban muy medidos y el candidato al que iba dirigida la pregunta del periodista tenía minuto y medio para responder, su adversario un minuto para la réplica y el primer candidato 30 segundos para cerrar el turno. Esa mecánica tan medida obligó a los candidatos a responder en lenguaje casi publicitario a cuestiones complejas de educación, economía, salud.

\section{h) Bush-Gore (2000)}

\footnotetext{
${ }^{12}$ CONTRERAS, José Miguel, Vida política y televisión, 1990. Espasa Calpe. Capítulo „Géneros de espacios políticos en televisión". Pag. 87-103
} 
En estas elecciones hubo tres debates presidenciales cara a cara. Estuvieron moderados por un mismo periodista: JimLehrer, presentador del principal informativo de la cadena de televisión pública PBS. Cada uno de los 3 programas tenía un formato distinto aunque los 3 duraron lo mismo: 90 minutos. Gore se presentaba después de 8 años de vicepresidente con Bill Clinton. Estaba mejor preparado intelectual y académicamente que Bush. El representante republicano había cometido errores durante la campaña y hasta ese momento no había conseguido dar la imagen presidencial que buscaba. El primer debate se celebró en Boston el 3 de octubre ante mil invitados y no respondió a les expectativas, ya que hubo en total 40 millones de audiencia (sumando la de la cadena $A B C, C B S$, algunas emisoras de la NBC y otras cadenas informativas de televisión por cable). Los candidatos estaban de pie con un atril y separados dos metros entre ellos. Gore abusó de un tono profesoral y arrogante y no logró superar a un George Bush que se mostró seguro de si mismo y logró alejar dudas sobre su supuesta falta de preparación para ocupar el Despacho Oval.

El segundo fue el 11 de octubre en Winston-Salem (Carolina del Norte). Tenían mayor proximidad física que en el primero y estaban sentados en una mesa en forma de U. Gore no llegó a conectar con el público pese a que se alejó del tono arrogante del primer debate. Sin embargo, su oponente aprobó el examen internacional (en la precampaña había salido en un programa de televisión y no sabía quién era el presidente de Pakistán y el de otros países que eran noticia en esos momentos). Bush exhibió conocimientos, ideas claras y espíritu estadista. Utilizó comentarios sencillos y directos que fueron más efectivos que los del candidato demócrata, quien además estuvo demasiado a la defensiva. El tercer debate fue en Missouri el 17 del mismo mes y los dos estaban de pie y sin atril. Disponían de una silla alta, tipo taburete, para descansar mientras el otro candidato respondía a alguna de las preguntas de los 144 indecisos que se encontraban en el plató y que habían sido previamente seleccionados. En alguna ocasión Gore y Bush se hablaron frente a frente. El republicano estuvo muy seguro e incluso hizo reír al público. El formato beneficiaba a Gore, ya que había debatido de esa forma en cientos de ocasiones y tenía un mejor control de la escena.

La celebración de los tres debates llegaron después de una precampaña donde George W. Bush y Albert Gore se habían alternado en las encuestas como ganadores. El objetivo de los partidos era hacerse con el voto de los indecisos e independientes, que en estas elecciones norteamericanas se había cifrado en torno al $10 \%$ del electorado. Sin embargo, los debates no deshicieron el empate técnico que ofrecían las encuestas antes de su celebración y no decidieron prácticamente nada, ya que el $96 \%$ del voto no cambió tras los tres espacios televisivos.

\subsection{El modelo francés}

\subsubsection{Definición}

El debate electoral por televisión en Francia tiene mucha raigambre aunque no en todas las elecciones se celebran, ya que depende de los intereses de los 
candidatos en cada momento. A diferencia del debate americano, Francia tiene configurado un modelo de debate que es un auténtico cuerpo a cuerpo entre los dos contendientes. Los aspirantes a la presidencia polemizan directamente bajo el arbitraje de uno o dos moderadores. Ellos suscitan los temas a tratar, a diferencia del debate americano, donde el panel de periodistas realizapreguntas individuales a los candidatos.

La posición en la que debaten los distingue también de los americanos porque aquí están situados de forma frontaly sentada. La concepción del debate en este país Francia no es la de un show sino la de un programa informativo serio donde los dos hombres que quieren ser presidentes de Francia debaten a fondo cuestiones importantes sin la aportación de la espectacularización de la televisión. De hecho, los debates no tienen programa previo y se inician directamente con los dos candidatos ya sentados y preparados para debatir. Además, a diferencia de los americanos, el debate en Francia no tiene público, lo que evidencia otra vez la ausencia de interés de convertirlo en un gran espectáculo y dejarlo en un programa estrictamente de carácter informativo.

\subsubsection{El nacimiento: Giscardd’Estaing - Mitterrand (1974)}

Se celebró 9 días antes de la segunda vuelta, el 10 de mayo de 1974, entre Valéry Giscardd"Estaing y François Mitterrand. Ambos habían quedado candidatos finalistas después de la primera vuelta. Era el primer debate televisivo que se celebraba en la historia de Francia y estuvo seguido por el $81 \%$ de los votantes. En aquellas elecciones, un $16 \%$ de los electores franceses siguieron la campaña electoral por televisión (Blumler, Cayrol, 1978) con la intención de que les ayudara a tomar la decisión de a quién votar, lo que refuerza la importancia de aquel debate. Giscardd"Estaing estuvo brillante y dejó frases lapidarias que tuvieron un gran efecto en la audiencia: "Usted es un hombre del pasado" o "Sr. Mitterrand, usted no tiene el monopolio del corazón", esta última como contestación contundente ante la enumeración de las clases sociales que Mitterrand decía que iba a defender si era presidente, como si el propio Giscard no pudiera entrar en ese coto al ser el representante de los afortunados.

El propio Giscardd"Estaing lo cuenta así en su libro "Le Pouvoir et la vie":

“... Creo que fui elegido presidente de la República gracias a esa frase de 10 palabras: ... Pero, señor Mitterrand, ! Usted no tiene el monopolio del corazón! ${ }^{13}$ Según él mismo dice, esa célebre frase le dio 500 mil votos, " yo he conservado esos votos y son ellos los que han asegurado mi victoria final": " Al mismo tiempo y sin saberlo, yo había entrado en el mundo de la comunicación moderna, en la que, según los especialistas, el mensaje debe ser corto, indeformable, accesible más a la sensibilidad que al razonamiento $y$, sobre todo, intensamente vivido! $Y$ fue intensamente vivido! ${ }^{14}$

\subsubsection{Otros debates hasta la actualidad}

\section{a) Giscardd'Estaign - Mitterrand (1981)}

\footnotetext{
${ }^{13}$ Ver en MUÑOZ ALONSO, Alejandro. Op. Cit. pag. 147-148.

${ }^{14}$ Ver en Giscardd'Estaing, 1988. ( pags.330-331)
} 
Tuvieron que pasar 7 años hasta que se celebrara otro debate presidencial. Tuvo lugar el 5 de mayo de 1981 y los protagonistas fueron los mismos contendientes que en 1974. Mitterrand estuvo más lúcido en aquel debate y en el transcurso de él se negó a contestar una pregunta de su oponente argumentando que no era su alumno. Pero si en el debate de 1974 Giscardd"Estaign patentó aquella famosa frase que según él decidió las elecciones, su contrincante, Mitterrand, le devolvió la moneda con otra frase para la historia de la política televisada: "Monsieur Giscardd'Estaing, vousêtesl'homme du passif' ( SeñorGiscardd"Estaing, usted es un hombre del pasado) ${ }^{15}$.

En este duelo hubieron dos moderadores: MichèleCotte y Jean Boissonat. Un comentarista, Jean Bothorel, escribió que "Ios pretendientes a la función suprema se explican, de manera cortés, es cierto, pero frontalmente". En este debate, Mitterrand puso una serie de condiciones bastante curiosas para la poca vigencia que tenían los debates en aquel momento, ya que era el segundo que se celebraba en Francia. Condiciones que se referían a la posición de los candidatos, el enfoque de las cámaras a los contendientes, el tiempo que debían estar, el tipo de cámara, el escenario, etc.

Una vez reconocidos los resultados electorales, el partido de Mitterrand hizo público el porqué de tanta concreción en los detalles del debate. Obedecía a que pretendían conseguir que los medios de comunicación fueran muy estrictos a la hora de dictaminar quién había sido el ganador, basándose en que si todos los medios de comunicación coinciden en dar como ganador a un candidato, esto se transforma en estado de opinión mientras que si hay diferentes opiniones en los medios no crea corriente de opinión en el electorado.

\section{b) Chirac-Fabius (1986)}

Al margen de las presidenciales, en las legislativas también se han producido debates electorales cara a cara. Laurent Fabius, entonces primer ministro, se enfrentó a Jacques Chirac en lucha por la Asamblea Nacional. Los autores no saben a ciencia cierta si este debate influyó en la victoria electoral del candidato de centro derecha pero lo cierto fue que éste tuvo un destacado papel.

\section{c) Mitterrand - Chirac (1988)}

Se celebró el 28 de abril y ambos candidatos aparecieron ya sentados en el set cuando la televisión conectó en directo. Su entrada entre flashes fue omitida de forma respetuosa. Chirac estuvo más brillante y convincente pero su agilidad dialéctica de poco le sirvió ante la imagen de calma que transmitía Mitterrand. Su actitud serena, aparentemente despreocupada por contestar a Chirac se basa en torno a la teoría del propio Mitterrand de que "en televisión cuenta menos lo que se dice que lo que se ve".

15 Drouot, Guy. Les campagnesélectoralesradiotélévisees. Collection Droit de I"Audiovisuel. Presses Universitariesd"Aix-Marseille Économica. 1995. Pag. 33 
La imagen tranquila de Mitterrand iba encaminada a conectar mejor con un electorado que en ese momento quería seguridad y calma. La imagen que Chirac transmitía era de activismo y exaltación con el slogan de campaña " "Lardeur", algo que, en ese momento inquietaba a los franceses, según los sociólogos. En contraposición aparecía Mitterrand con "Laforcetranquille".

\section{d) Juppé-Jospin (1997): sin debate}

En las elecciones legislativas de mayo de 1997 no hubo cara a cara entre los dos candidatos. Jospin propuso uncara a cara a su contrincante conservador Alain Juppé, que se presentaba a la reelección. Pese al empate técnico en las encuestas el conservador no quiso someterse a un mano a mano con el socialista y optó como excusa por proponer un debate entre 4 con las incorporaciones de Léotard y el comunista Robert Hue. A Jospin no le interesó este formato y no hubo cara a cara.

\section{e) Tampoco en 2002}

Francia celebró en 2002 las Elecciones Presidenciales y las Legislativas. Ni unas ni otras tuvieron debates cara a cara. Las presidenciales celebraron la $1^{\text {a }}$ vuelta el 21 de abril. En ese periodo electoral no debatieron los máximos candidatos, Jacques Chirac, Lionel Jospin, Jean Pierre Chevenement y/o el ultraderechista Jean Marie Le Pen. En la $2^{a}$ vuelta, que se celebró el 5 de mayo, el candidato Chirac no le concedió el debate al ultra Le Pen, quien contra todo pronóstico había pasado a la segunda vuelta en detrimento del socialista Lionel Jospin. La primera vuelta de las legislativas se celebraron el 9 de junio pero durante esa campaña electoral el primer ministro JeanPierre Raffarin se negó a debatir en televisión con el primer secretario del Partido Socialista, François Hollande.

\subsection{El modelo alemán}

\subsubsection{Definición del modelo}

En los debates cara a cara no hay panel de periodistas. Cuando se trata de programas con más candidatos sí suele haber periodistas que formulan preguntas y también presencia de público en el estudio. Sin embargo los debates entre los dos máximos representantes de los partidos mayoritarios se celebran sin la presencia de público y con el arbitraje de uno o dos moderadores. No se trata de un cara a cara, como es el francés, se trata de una comparecencia conjunta para responder a unas preguntas lanzadas por el moderador, aunque a lo largo del programa puede darse la circunstancia de que se enzarcen en una batalla dialéctica. A diferencia del debate americano, el debate alemán, al igual que el francés, no supone un show televisivo. Sin embargo, sí que se parece al americano en cuanto a la disposición física de los candidatos, ya que suele ser de pie y con atril.

\subsubsection{Los debates alemanes}

Hasta las Elecciones de 2002, las conocidas como "ruedas de elefante" tan sólo 
se habían dado en cinco campañas: 1972, 1976, 1980 y 1987, aunque no siempre enfrentaron a candidatos con opciones claras de ganar las elecciones. No han habido más debates porque la decisión de participar recae en los propios candidatos mismos, ya que no están establecidos por ley, y éstos acuden en función de sus intereses particulares y puntuales en cada campaña. A diferencia de los Estados Unidos, donde los grandes debates televisivos de los candidatos presidenciales en las campañas electorales desempeñan un importante papel y han propiciado una considerable actividad investigadora, el número de los estudios en Alemania que se han ocupado de los debates es muy corto. En cualquier caso las cadenas de televisión organizan antes de cada votación un número de discusiones con otros representantes de los partidos, mientras que los candidatos a la cancillería en los últimos años tan sólo eran vistos en entrevistas personales.

Un análisis realizado por los investigadores Norpoth y Baker ${ }^{16}$ demuestra que en las discusiones televisivas de 1972 hasta 1980 los partidos políticos habían sido cada vez menos objeto de valoraciones, a diferencia de los candidatos. En este estudio también se aprecia un bonus oficial o bonus del canciller. El canciller era con diferencia el más mencionado; la oposición tuvo su culpa en ello, ya que lo había convertido en el blanco de todos sus ataques. Es por ello que tanto el gobierno como el partido gobernante estuvieran en el centro de todas las discusiones.

\subsubsection{Kohl se negó a debatir}

El canciller Helmut Kohl, quien gobernó entre 1982 y 1998, nunca aceptó el envite cuerpo a cuerpo lanzado por los candidatos socialdemócratas, ya que temía que el debate les beneficiara. Kohl no quiso asumir el riesgo de medir argumentos, personalidades, aspecto físico y lenguaje corporal con sus oponentes.

\subsubsection{Schröeder-Stoiber (2002)}

Por primera vez en la historia de Alemania un canciller aceptó un cara a cara en televisión. Fue con motivo de las elecciones de 2002. Gerhard Schröeder (SPD), que se presentaba a la reelección, admitió el reto de su contrincante conservador Edmund Stoiber (CDU). El candidato socialdemócrata fue retado varios meses antes de las elecciones y accedió desde su pedestal de monstruo televisivo, ya que tenía una confianza plena en su encanto mediático. De hecho sus asesores propusieron al partido conservador que los debates se realizasen los últimos días antes de las elecciones, cuando ya hubiese sido demasiado tarde corregir en la opinión pública una eventual imagen desfavorable. Por contra, el líder del CDU era antes de la campaña electoral un político al que le costaba hablar con soltura y decir frases concluyentes para los telespectadores aunque mejoró mucho antes del primer debate, posiblemente por el entrenamiento al que fue sometido.

\footnotetext{
${ }^{16}$ NORPOTH Helmut y BAKER, Kendall L. Politikeruntersich am Bildschirm: Die Konfrontation von personen und Sachthemen in den Fernsehdiskussionen 1972-1980. In Max Kaase\& Hans-Dieter Klingemann (Hrsg.), Wahlen und potitisches System. AnalysenausAnlab der Bundestagswahl 1980 (S.600-621). Opladen: WesdeutscherVerlag.
} 
Fueron dos los debates que se celebraron en esas elecciones. El primero tuvo lugar el 25 de agosto y el segundo el 8 de septiembre. Ambos tuvieron una duración de 75 minutos. El primero fue emitido por las dos cadenas líderes de la televisión privada, la RTL y la SATL y dos de sus presentadores entrevistadores estrella tuvieron la misión de moderarlo. El segundo estuvo moderado por dos conocidas presentadoras de la televisión pública. El formato establecía normas rígidas que impedían el cara a cara, de hecho durante los debates sólo se miraron de reojo aunque en alguna contada ocasión se intercambiaron algún comentario directo a los ojos en forma de reproche. Los dos candidatos se dirigieron siempre a los moderadores, nunca a la cámara de forma directa, ni al oponente. Cada una de las periodistas lanzaba una pregunta a un candidato, que tenía 90 segundos para la contestación, 60 segundos para la réplica y otros 60 para la contrarréplica.

Respecto al escenario, el del segundo debate era vanguardista y se encontraba levantado respecto al suelo con dos partes claramente diferenciadas: la de los candidatos y la de las moderadoras. El decorado era totalmente neutro en tonos azules y grises. Los moderadores estaban de espaldas a la cámara para facilitar una realización más al estilo americano. Una realización que incluía planos escorzo ${ }^{17}$ entre ambos candidatos y algún primer plano. Los candidatos debatían de pie detrás de atriles grandes, que contenían un vaso de agua y un micrófono con soporte.

En los dos debates, los dos candidatos vistieron traje oscuro y camisa blanca en tono apagado (para no hacer reflejos). Stoiber cambió la corbata negriblanca por la rojiblanca en el segundo debate mientras que Schröeder apostó por la rojiblanca (rayas suaves) en ambos duelos. De hecho, en el segundo debate las dos corbatas de los candidatos eran iguales. En el segundo debate, Stoiber pareció más maquillado que el candidato socialdemócrata. Una muestra de la veteranía ante las cámaras de Schröeder lo confirma este detalle: acabado el segundo debate, se dirigió al lugar donde Stoiber estaba tras su atril para darle la mano, lo que captaron las cámaras de la televisión, un gesto estudiado que siempre queda bien ${ }^{18}$.

Aunque Schröeder ganó por una leve ventaja el primer debate según las encuestas, su contrincante apareció en varias ocasiones como más combativo, contundente y preparado. Sin embargo, en el cómputo general los sondeos indicaron que la mayoría de los espectadores consideró más convincente, cualificado y simpático al político socialdemócrata. También ganó el canciller a los puntos en el segundo debate, ya que mostró mucho aplomo y soltura. Con argumentos convincentes, pequeñas puyas y alguna broma, logró que los sondeos le dieran como ganador en prácticamente todas las categorías (simpatía, credibilidad y claridad) frente a un Stoiber que fue considerado mejor que su

\footnotetext{
${ }^{17}$ El plano escorzo indica las reacciones de una persona que escucha tomando como referencia la cámara situada desde la persona que habla. Tanto el escorzo como el primer plano y el plano escucha son muy atractivos para el telespectador pero no son habituales en debates, ya que ofrecen mucha información y los equipos asesores pactan la no inclusión de este tipo derecursos.

${ }^{18}$ Felipe González hizo el mismo gesto en el debate de Antena 3 de 1993 cuando acabado el programa, raudo se levantó para ir a darle la mano a José María Aznar.
} 
oponente sólo en temas económicos.

\subsection{El debate en otras partes del mundo}

Suecia es el primer país europeo que comenzó a celebrar debates por televisión. Se trata de una continuidad a los que inició en la radio en los años 30. Las primeras experiencias consistían en un debate que duraba varias horas entre los candidatos pocos días antes de las elecciones. En la actualidad también se celebran cara a cara entre los candidatos principales ${ }^{19}$.

En Italia únicamente se ha realizado un debate. Fue en la campaña de 1983 y debatieron E.Berlinguer y C. de Mita. En Rusia se celebraron los primeros debates en la campaña de las Elecciones Legislativas de 1989 y fueron organizadas por las televisiones locales al no tratarse de elecciones presidenciales. En ellas participó Yeltsin por primera vez en un debate. En Gran Bretaña, su bipartidismo y su parlamentarismo, les permite enfrentarse dos veces por semana con mucha proximidad física en la cámara de los Comunes pero no es habitual que se realicen debates cara a cara ex profeso en un plató de televisión durante una campaña electoral. A veces han habido intentos, como el de John Major, quién reclamó un debate al laborista Neil Kinnock. Éste se negó a debatir y el conservador le batió contra todo pronóstico acabando su ingeniosa campaña sobre una humilde caja de cartón de detergente. En las elecciones de 1997 Blair no aceptó el cuerpo a cuerpo que le propuso el en ese momento presidente John Major.

En Portugal se realizan desde 1983. También tienen experiencias de debate en Portugal, Bélgica, Dinamarca, Finlandia, Irlanda, Noruega y Austria. En este último país, en las Elecciones de 2002 participaron los cuatro principales candidatos a la cancillería. Japón es otro de los países donde se han celebrado debates. En Sudamérica, en países como Chile, México, Colombia, Perú y Brasil. En el país canarinho, en las Elecciones Presidenciales de 2002 hubo debates a 4 y a 2 bandas. Uno en la primera vuelta entre los 4 candidatos presidenciales: LuizInacio Lula da Silva del Partido de los Trabajadores (PT), el candidato oficialista, José Serra, perteneciente al Partido del Movimiento Democrático Brasileño (PMDB) y ex ministro del entonces presidente Fernando Henrique Cardoso, Ciro Gomes, candidato del Partido Popular Socialista (PPS) y Anthony Garotinho. El decorado de este debate estaba inspirado en colores de la bandera del país. Constaba de un panel verde y amarillo cortado por 5 rayas negras. Los candidatos debatían de pie detrás de un atril de grandes dimensiones y de diseño vanguardista. El ganador de la primera vuelta fue Lula con el $46 " 4 \%$ de los votos y José Serra fue el segundo con el 23 " $2 \%$. Ambos fueron los protagonistas de un debate presidencial que presenciaron 80 millones de personas y que fue organizado por la red televisiva Globo. El formato cambió respecto al debate a 4 de la primera vuelta, ya que Lula y José Serra no tenían atril delante de ellos. Se trató de un debate parecido al tercero y último que protagonizaron Bush y Gore en 2000. Con

\footnotetext{
19 . Ver ROSPIR Zabala, Juan Ignacio, Democracia mediática y campañas electoralesOp. Cit. Anterior Pag.78
} 
público en el plató y cerca de ellos, los candidatos contestaban de pie a las preguntas que previamente habían sido escogidas por la televisión de entre las presentadas por un grupo de 53 personas seleccionadas en todo el país. Estos electores se declaraban aún indecisos sobre su voto, y habían estado encerrados en un hotel de Río incomunicados con el mundo exterior para no ser influenciados. Realizaron preguntas concretas. La primera la hizo una mujer ¿Cómo esos millones de brasileños con un sueldo base de 200 reales (50 dólares) podrán comprarse un piso? Respecto al vestuario, José Serra lució traje oscuro, camisa blanca y corbata con rayas. Lula, al igual que en el debate a 4 de la primera vuelta, vistió chaqueta azul oscura, camisa blanca y corbata roja con rayas blancas. Los dos, a diferencia del primer debate, llevaban un adorno en la solapa, Lula una especie de estrella bastante vistosa y Serra una pieza un poco más discreta. Ambos valoraron el debate nada más acabar.

En Colombia, en las elecciones de 1984 se celebró uno entre Andrés Pastrana y Ernesto Samper, que se presentaba a la reelección. En Perú en la elección municipal para la ciudad de Lima (más de 6 millones de habitantes), un planteamiento coordinado de dos candidatos frente a otros dos hizo que uno de ellos, Barrantes, lograra el éxito en la campaña electoral. En los dos debates substanciales que hubo las posturas fueron claras. Ricardo Amiel, el candidato del PPC, era un entendido de Lima. Se suponía que iba a ser el ganador, ya que era un gran comunicador, además era periodista e ingeniero, pero en el debate adoptó una posición pasiva y negativa. Por otro lado, los otros dos candidatos eran los outsiders. Barrantes, candidato de Izquierda Unida, que en principio disponía de pocas posibilidades, fue sumando puntos y resultó al final el verdadero ganador. A raíz de estos debates los dos candidatos que estaban mejor situados, los jóvenes Barrenechea y Amiel, sufrieron un retroceso y permitieron la victoria de Barrantes. 